\title{
THE COAGULATION DEFECT IN HEMOPHILIA: STUDIES OF THE CLOT PROMOTING ACTIVITY ASSOCIATED WITH PLASMA EUGLOBULIN IN HEMOPHILIA ${ }^{1}$
}

\author{
By EUGENE L. LOZNER AND F. H. L. TAYLOR \\ (From the Thorndike Memorial Laboratory, Second and Fourth Medical Services (Harvard) \\ of the Boston City Hospital, and the Department of Medicine, Harvard Medical School, \\ Boston)
}

(Received for publication July 17, 1939)

Normal human cellular-free citrated plasma ${ }^{2}$ contains a substance which acts to decrease the coagulation time of the blood in hemophilia (1, 2). The observation of Patek and Taylor (3) that this activity is associated or co-precipitated with certain fractions of the plasma proteins has recently been confirmed by Howell (2). Both Howell's experiences and those in this laboratory would indicate that the clot-promoting power is associated with the globulin portion of the plasma proteins, whether prepared by salting out (2), acid precipitation $(2,3)$ or dialysis $(3)$.

During the past two years a study of the nature of "globulin substance" prepared by dilution and acid precipitation of plasma has been made $(3,4$, $5)$. It was determined that the protein precipitates obtained between $\mathrm{pH} 5.5$ and 6.0 are associated with the largest proportion of clot-promoting activity. The active factor contained in such precipitates was found to be thermolabile, soluble in isotonic salt solution, and capable of being passed through a Berkefeld filter. It is rapidly destroyed by alkali and by prolonged standing in neutral solution. Solutions of "globulin substance" behave in a quantitative manner with respect to their ability to accelerate clot formation of hemophilic blood in vitro. Single injections of this acidprecipitated "globulin substance" into patients with hemophilia result in a prompt fall in the co-

1 The expenses of this investigation were defrayed in part by a gift to Harvard University from the Smith, Kline and French Laboratories of Philadelphia and by a grant given in honor of Francis Weld Peabody by the Ella Sachs Plotz Foundation.

2 Hereafter the word "plasma" refers to plasma prepared from fresh normal human whole blood to which sodium citrate was added to make the final citrate concentration 0.25 per cent. This was then centrifuged 30 minutes at 2000 r.p.m., filtered through two thicknesses of Number 2 Whatman paper and passed through a Berkefeld V filter. agulation time of their circulating blood. Injections of such solutions repeated every six hours however, produce a transitory refractory phase during which the coagulation time returns to the former prolonged values. At the height of the refractory period when injections of solutions of "globulin substance" are no longer effective, an injection of whole Berkefelded plasma shortens the coagulation time. It was suggested that a possible explanation of this phenomenon might lie in the presence of a factor in normal plasma which was lost in the acid precipitation of the "globulin substance." The dilution of the plasma necessary to precipitate "globulin substance" effectively by acid precluded a satisfactory investigation of this hypothesis. Thus the globulin fraction was prepared by dialysis which allowed a partition of the plasma that could be more easily investigated. In comparison with the acid-precipitated material, the globulin prepared by dialysis has the advantages of freedom from foreign reagents, maximum solubility in isotonic saline, and closer physico-chemical definition as "euglobulin." Euglobulin is used here in the commonly accepted sense as that portion of the plasma proteins which is insoluble in distilled water but soluble in isotonic saline. The present communication presents certain observations on the euglobulin of the blood plasma with particular respect to its clot-promoting power for hemophilic blood both in vitro and in vivo and indicates certain differences existing between such preparations and those obtained by acid precipitation.

\section{METHODS}

Measured amounts of fresh Berkefelded citrated normal human plasma were pipetted into cellophane tubes and dialyzed against running tap water for eight days. The temperature of the water remained between $4^{\circ}$ and $6^{\circ} \mathrm{C}$. As dialy- 
sis proceeded, a precipitate of euglobulin separated. When dialysis was complete, the contents of the tube were washed into $250 \mathrm{ml}$. centrifuge cups and spun for 15 minutes at 2000 r.p.m. The supernatant liquid containing those plasma substances which were water soluble and non-dialyzable was decanted and the precipitate washed twice with distilled water. $^{8}$ The washings were discarded. The plasma euglobulin and the supernatant substances were then dried by the "lyophile" process. To facilitate injections, the euglobulin from each $75 \mathrm{ml}$. of blood plasma was redissolved in $50 \mathrm{ml}$. of saline and an equivalent quantity of the supernatant substances was redissolved in $50 \mathrm{ml}$. of distilled water. In order to avoid deterioration, an amount of the dry material sufficient to carry out each observation was made up into solution immediately before use. The solutions of the plasma euglobulin and the supernatant substances were then passed through a Berkefeld filter and transferred under sterile conditions to rubber-capped vials and kept in the ice box until the time of injection. Three separate preparations of plasma euglobulin were investigated. For each preparation $600 \mathrm{ml}$. of fresh-pooled normal human plasma were used. The methods of injection of the material, and the determination of coagulation times, and of the activity of various preparations to be studied have been fully described elsewhere (4).

\section{EXPERIMENTAL}

The clot-promoting activity in vitro of plasma euglobulin and supernatant substances. To varying amounts of the saline solution of plasma euglobulin and water solution of the supernatant substances, $2 \mathrm{ml}$. of blood from a patient with hemophilia were added according to the standard technique previously described (2). Each of the three preparations was tested on blood from at least two patients. One dilution, $0.05 \mathrm{ml}$. of the solutions to be tested to $2 \mathrm{ml}$. of hemophilic blood, only, was used of the third preparation. The results are given in Table I. It will be observed that the saline solution of plasma euglobulin was optimally active and behaved in a quantitative man-

\footnotetext{
8 Hereafter these substances will be referred to as supernatant substances and plasma euglobulin respectively.
}

TABLE I

The clot-promoting activity for hemophilic blood in vitro of plasma euglobulin and supernatant substances

\begin{tabular}{|c|c|c|c|c|}
\hline $\begin{array}{l}\text { Preparation } \\
\text { number }\end{array}$ & $\begin{array}{l}\text { Patient } \\
\text { number }\end{array}$ & $\begin{array}{l}\text { Ml. added } \\
\text { to } 2 \text { ml. } \\
\text { hemophilic } \\
\text { blood }\end{array}$ & $\begin{array}{l}\text { Saline } \\
\text { solution of } \\
\text { plasma } \\
\text { euglobulin } \\
\text { Coagula- } \\
\text { tion time } \\
\end{array}$ & $\begin{array}{c}\text { Water } \\
\text { solution of } \\
\text { supernatant } \\
\text { substances } \\
\text { Coagulation } \\
\text { time } \\
\end{array}$ \\
\hline Jan. 17,1939 & 1 & \begin{tabular}{|c|} 
millititers \\
0 (control) \\
.01 \\
.05 \\
.10
\end{tabular} & $\begin{array}{c}\text { minutes } \\
172 \\
73 \\
12 \\
11\end{array}$ & $\begin{array}{c}\text { mirutes } \\
172 \\
142 \\
53 \\
42\end{array}$ \\
\hline 1. & 2 & $\begin{array}{c}0 \text { (control) } \\
.01 \\
.05 \\
.10\end{array}$ & $\begin{array}{l}32 \\
20 \\
14 \\
10\end{array}$ & $\begin{array}{l}32 \\
32 \\
25 \\
15\end{array}$ \\
\hline Feb. 6, 1939 & 2 & $\begin{array}{c}0 \text { (control) } \\
.01 \\
.05 \\
.10\end{array}$ & $\begin{array}{r}45 \\
16 \\
9 \\
5\end{array}$ & $\begin{array}{l}45 \\
49 \\
27 \\
27\end{array}$ \\
\hline 2. & 3 & $\begin{array}{c}0 \text { (control) } \\
.01 \\
.05 \\
.10\end{array}$ & $\begin{array}{r}139 \\
20 \\
9 \\
7\end{array}$ & $\begin{array}{r}139 \\
113 \\
40 \\
22\end{array}$ \\
\hline Feb. 24,1939 & 2 & $\begin{array}{c}0 \text { (control) } \\
.05\end{array}$ & $\begin{array}{l}44 \\
12\end{array}$ & $\begin{array}{l}44 \\
40\end{array}$ \\
\hline 3. & 3 & $\begin{array}{c}0 \text { (control) } \\
.05\end{array}$ & $\begin{array}{r}110 \\
10\end{array}$ & $\begin{array}{r}110 \\
29\end{array}$ \\
\hline 3. & 4 & 0 (control) & $\begin{array}{l}65 \\
11\end{array}$ & $\begin{array}{l}65 \\
37\end{array}$ \\
\hline 3. & 5 & $\begin{array}{c}0 \text { (control) } \\
.05\end{array}$ & $\begin{array}{r}106 \\
12\end{array}$ & $\begin{array}{r}106 \\
40\end{array}$ \\
\hline
\end{tabular}

ner in reducing the coagulation time of hemophilic blood. The solution of the supernatant substances however, contained only small amounts of activity.

The effect of a single intravenous injection of plasma euglobulin on the coagulation time of the blood of a patient with hemophilia. A patient with hemophilia was given a single intravenous injection of $50 \mathrm{ml}$. of the saline suspension of the euglobulin derived from $75 \mathrm{ml}$. of normal human plasma. The coagulation time fell abruptly from 110 minutes to 32 minutes in the course of the first hour after injection and remained below 40 minutes for 11 hours, after which it slowly returned to pre-injection levels, reaching a value of 120 minutes 43 hours after injection. The results are given in graphic form in Figure 1. These results are in every way comparable to those reported for the effect of the injection of Berkefelded normal human plasma (1). 


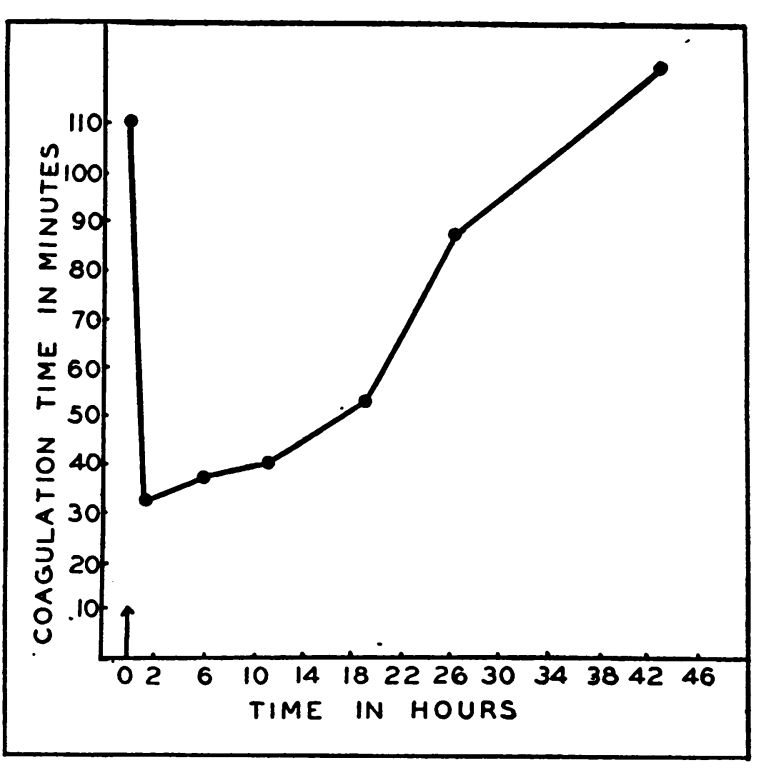

Fig. 1. The Effect of a Single Intratenous INjection (arrow) of Plasma Euglobulin on the Blood Congulation Time of a Patient with Hemophilia

The effect of multiple intravenous injections of plasma euglobulin on the coagulation time of the blood of patients with hemophilia. Observations concerning multiple intravenous injections of normal plasma euglobulin were made on three patients with hemophilia having blood coagulation times of 32,105 , and 139 minutes respectively. In each case, $50 \mathrm{ml}$. of the saline solution of euglobulin derived from $75 \mathrm{ml}$. of normal human plasma were injected intravenously at 6-hour intervals for varying periods of time. The results obtained in one patient are described here and summarized graphically in Figure 2. The results obtained in the other two patients were entirely similar. Following the first injection of plasma euglobulin, the coagulation time was found to have fallen in one hour from 139 to 23 minutes. Five hours after this injection the coagulation time had risen to 42 minutes but was brought back to 27 minutes by a second injection of $50 \mathrm{ml}$. of euglobulin substance. The injections were repeated every 6 hours until 42 hours after the first injection. In each instance the patient responded with a fall in the coagulation time of his blood. Thirteen hours after the last injection the coagulation time had risen to $77 \mathrm{~min}$ utes and in 26 hours had returned to a level of 122 minutes, at which time observations were discontinued. There was at no time any indication of a refractory period such as occurs accompanying multiple injections of acid-precipitated "globulin substance" $(4,5)$. The reader is invited to compare Figure 2 of this communication with Figures 1,2 and 3 of reference 5 .

The effect of a single intravenous injection of supernatant substances from normal human plasma on the coagulation time of the blood in hemophilia. Fifty ml. of the water solution of the supernatant substances derived from $75 \mathrm{ml}$. of plasma were injected intravenously into a patient with hemophilia. The coagulation time of the patient's blood fell from 44 minutes to 38 minutes in the course of one hour and was 40 minutes five hours later. The difference in these figures is of no significance as these coagulation times are well within the range of the variations recorded for coagulation time in this patient on previous occasions. The coagulation time of the blood of this same patient on another occasion was sharply reduced from 32 minutes to 15 minutes following the injection of $50 \mathrm{ml}$. of the saline solution of the euglobulin derived from $75 \mathrm{ml}$. of the same parent plasma. The administration of the supernatant substances in the case of a second patient failed to produce any fall in the coagulation time of his blood when the material was injected intravenously six hours after an effective injection of plasma euglobulin.

\section{DISCUSSION}

The present investigations indicate that the clotpromoting power of normal human plasma for hemophilic blood is associated with the plasma euglobulin. Plasma euglobulin preparations are active in reducing the coagulation time of hemophilic both in vivo and in vitro. In the latter instance, their action appears to be quantitative. The coagulating activity of the supernatant substances containing the water soluble non-dialyzable portion of the plasma, however, is comparatively very slight. These findings are confirmatory of previous experiences in this laboratory and also of those of Howell who finds that most of the clotpromoting activity of plasma is associated with euglobulin and fibrinogen when such substances are prepared from plasma by salting-out methods. Howell has also shown that the clot-promoting substance is not fibrinogen, since coagulating activity remains in his preparation after the removal 


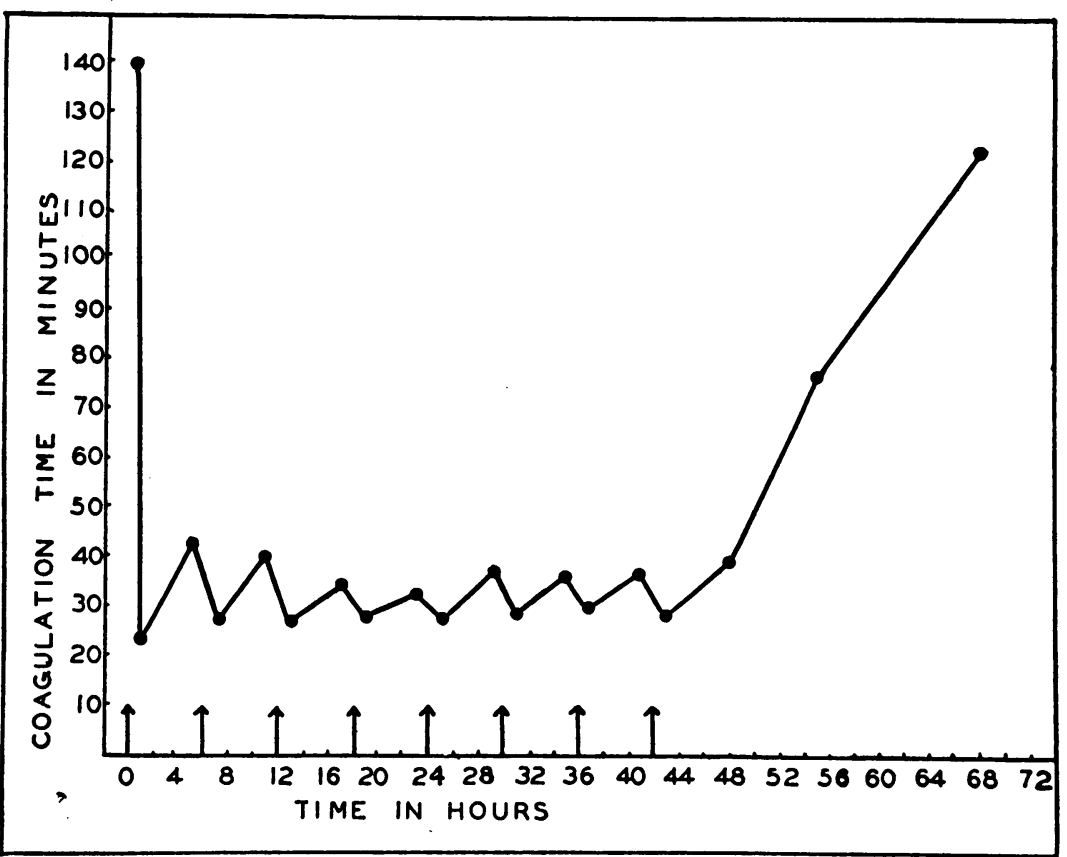

Fig. 2. The Effect of Multiple Intravenous Injections (arrows) of Plasma Euglobulin on the Blood Coagulation time of a Patient with HEMOPHILIA

of this protein. It has recently been shown (6) that plasma freed from both fibrinogen and prothrombin possesses clot-promoting activity. It appears evident, therefore, that while a clot-promoting substance is to be found in close association with the fibrinogen and euglobulin of the blood plasma, its identity with any given protein contained therein cannot be assumed. However, it may well be in combination with these proteins or co-precipitated with them.

The difference between the behavior of plasma euglobulin observed here and that previously observed for acid-precipitated "globulin substance" was quite unexpected. Single injections of both plasma euglobulin and "globulin substance" into hemophilic patients produce a prompt decrease of blood coagulation time. The duration of the effect following the injection of plasma euglobulin seems to be greater than that previously described for "globulin substance." In all other respects, single injections of these substances behave similarly and resemble the effect of an injection of the parent plasma from which they are derived. Repeated injections of plasma euglobulin, in sharp contrast to those of "globulin substance," behave in a comparable manner to injections of whole plasma, in that they are capable of maintaining the coagulation time at the lowered level with no indication of a refractory period which develops after injections of "globulin substance." It would seem, therefore, that plasma euglobulin presented a more reasonable starting point for further fractionation than that offered by acid-precipitated "globulin substance."

\section{SUMMARY AND CONCLUSIONS}

1. Dialysis of cellular-free citrated normal human plasma yields a euglobulin precipitate containing practically all of the clot-promoting activity of the plasma for hemophilic blood.

2. Unlike acid-precipitated "globulin substance," plasma euglobulin resembles normal human plasma in its ability to maintain in hemophilia a reduced level of the blood coagulation time when injected intravenously every six hours.

\section{BIBLIOGRAPHY}

1. Patek, A. J., Jr., and Stetson, R. P., Hemophilia; abnormal coagulation of blood and its relation to blood platelets. J. Clin. Invest., 1936, 15, 531. 
2. Howell, W. H., Hemophilia. Bull. New York Acad. Med., 1939, 15, 3.

3. Patek, A. J., Jr., and Taylor, F. H. L., Hemophilia; some properties of substance obtained from normal human plasma effective in accelerating coagulation of hemophilic blood. J. Clin. Invest., 1937, 16, 113.

4. Pohle, F. J., and Taylor, F. H. L., Coagulation defect in hemophilia. Effect in hemophilia of intramuscular administration of globulin substance derived from normal human plasma. J. Clin. Invest., 1937, 16, 741.
5. Pohle, F. J., and Taylor, F. H. L., Coagulation defect in hemophilia. Studies on refractory phase following repeated injections of globulin substance derived from normal human plasma in hemophilia. J. Clin. Invest., 1938, 17, 779.

6. Lozner, E. L., Kark, R., and Taylor, F. H. L., The coagulation defect in hemophilia. The clot promoting activity in hemophilia of Berkefelded normal human plasma free from fibrinogen and prothrombin. J. Clin. Invest., 1939, 18, 603. 